Fall 2016

\title{
An Integrated Model of Safer Sex Practices among African- American Gay and Bisexual Men
}

\author{
Brian D. Zamboni \\ University of Minnesota \\ Isiaah Crawford \\ University of Puget Sound \\ Fred B. Bryant \\ Loyola University Chicago, fbryant@luc.edu
}

Follow this and additional works at: https://ecommons.luc.edu/psychology_facpubs

Part of the Psychology Commons

\section{Recommended Citation}

Zamboni, Brian D.; Crawford, Isiaah; and Bryant, Fred B.. An Integrated Model of Safer Sex Practices among African-American Gay and Bisexual Men. Journal of Black Sexuality and Relationships, 3, 2: 75-98, 2016. Retrieved from Loyola eCommons, Psychology: Faculty Publications and Other Works,

http://dx.doi.org/10.1353/bsr.2016.0029

This Article is brought to you for free and open access by the Faculty Publications and Other Works by Department at Loyola eCommons. It has been accepted for inclusion in Psychology: Faculty Publications and Other Works by an authorized administrator of Loyola eCommons. For more information, please contact ecommons@luc.edu. cc) (i) $\Theta$

This work is licensed under a Creative Commons Attribution-Noncommercial-No Derivative Works 3.0 License. (C) 2017 James C. Wadley 


\title{
An Integrated Model of Safer Sex Practices among African-American Gay and Bisexual Men
}

\author{
BRIAN D. ZAMBONI,
}

University of Minnesota Medical School

ABSTRACT-Models of safer sex enable researchers to identify specific constructs that can be used to promote health behavior and are more effective than interventions without a theoretical base. This study tested basic and modified forms of the Theory of Reasoned Action and Information Motivation Behavioral Skills models among 151 African American gay/bisexual men. Gay socialization was added to an integrated model to see if this minority-specific contextual variable would improve the model. Self-efficacy was tested as an independent variable and a mediating variable. The results suggest that an integrated model of safer sex practices should include benefits/barriers to condom use, social norm perceptions, sexual assertiveness, and self-efficacy (as a mediating variable). Gay socialization did not improve the model statistically but may influence safer sex behavior conceptually and pragmatically.

KEYwORds - theory, gay, African American, safer sex, condom

CONTACT—Correspondence for this article should be addressed to: Brian D. Zamboni, Ph.D., L.P., Program in Human Sexuality, Department of Family Medicine and Community Health, University of Minnesota Medical School, 1300 South 2nd Street, Suite 180, Minneapolis, MN 55454 or at bzamboni@umphysicians.umn.edu. 

nosed with HIV/AIDS than Caucasian gay and bisexual men (Rosenberg, Millett, Sullivan, Del Rio, \& Curran, 2014). Thus, African-American gay/bisexual men remain at high risk for HIV infection (Center for Disease Control, 2015). Scholars have noted that more theorybased interventions are needed with African American gay/bisexual men (Hergenrather, Emmanuel, Durant, \& Rhodes, 2016). Models of safer sex enable researchers to identify specific constructs that can be used to promote health behavior and are more effective than interventions without a theoretical base (Albarracin et al., 2005). The Theory of Reasoned Action and the Information Motivation Behavioral Skills models have often been used to understand and promote safer sex. The two models provide both unique and overlapping predictors of sexual health behavior, but they have not always been used with African American gay/bisexual men. Also, structural equation modeling has not consistently been used to assess these paradigms.

African Americans may be less likely to identify as gay/bisexual because of heterosexist biases within the African-American community. Consequently, they may be less apt to seek HIV preventive services (O'Leary et al., 2007), an idea that has been supported in research (Knox, Sandfort, Yi, Reddy, \& Maimane, 2011). African-American gay/bisexual men experience the dual minority stressors of heterosexism and racism, which places them at risk for various mental health challenges and sexually transmitted infections (Crawford, Allison, Zamboni, \& Soto, 2002; David \& Knight, 2008; Meyer, 2010). Research is needed to show the degree to which the Theory of Reasoned Action and the Information Motivation Behavioral Skills models are applicable to African-American gay/bisexual and if adding contextual variables that are pertinent to this population should be included. Using structural equation modeling, these models will be tested with AfricanAmerican gay/bisexual men with the goal of producing an integrated model that contains key predictors of safer sex behavior. The literature review will start with an overview of the Theory of Reasoned Action, followed by an overview of the Information-Motivation-Behavioral Skills and a conceptual comparison of these theories.

\section{The Theory of Reasoned Action}

According to the Theory of Reasoned Action (TRA) (Fishbein \& Ajzen, 1975), intention to practice safer sex is shaped by attitudes toward condoms 


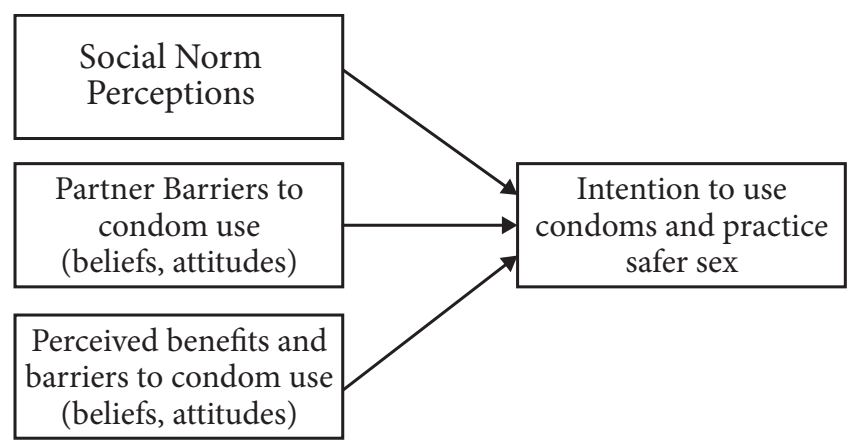

Fig. 1. Visualization of the Theory of Reasoned Action model.

and/or safer sex, expected benefits/costs of the sexual health behavior, and perceptions of social norms of the sexual health behavior (ThompsonLeduc, Clayman, Turcotte, \& Legare, 2015).

Attitudes toward condoms, expected consequences of condom use, and perceived social norms for condom use have predicted intentions to use condoms in several studies (Mitchell, Garcia, Champeau, Harvey, Petroll, 2012; Norris \& Ford, 1995; Zhang, Jemmott, \& Jemmott, 2015), including studies that involve gay/bisexual African-American men (Jemmott et al., 2014; Rosario et al., 1999). One study using structural equation modeling found support for the theoretical notions of the TRA among Caucasian gay males (Cochran, Mays, Ciarletta, Caruso, \& Mallon, 1992).

The TRA was modified to include perceived behavioral control (Ajzen, 1988), which refers to a person's perceived ability to manage a course of action. In this revision, called the Theory of Planned Behavior, attitude toward sexual health behavior, subjective norm, and perceived behavioral control are correlated and each predict safer sex intentions (Ajzen, 1991; ThompsonLeduc et al., 2015).

In a study of gay men, high levels of perceived behavioral control and social norm perceptions for condom use predicted safer sex practices (Godin, Savard, Kok, Fortin, \& Boyer, 1996; Mitchell et al., 2012).

Conceptually, perceived behavioral control appears to be similar to selfefficacy. Social cognitive theory (Bandura, 1990) postulates that health protective behavior results from a judgment of self-efficacy (i.e., perceived self-confidence to practice safer sex). Meta-analyses (e.g., Lacefield, Negy, Schrader, \& Kuhlman, 2015; Sheeran et al., 1999) support the notion that higher levels of self-efficacy predict higher levels of condom use (see also 


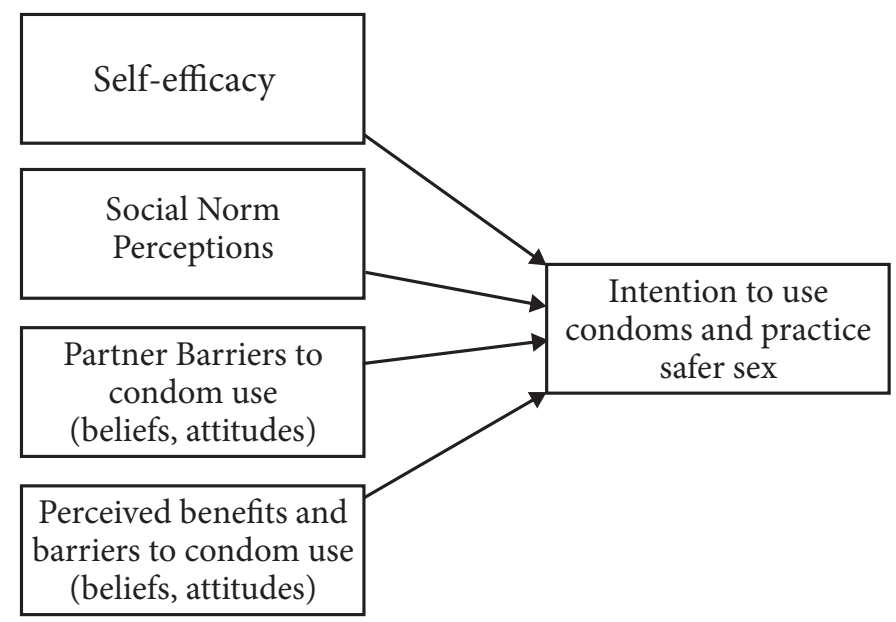

Fig. 2. Visualization of the Theory of Planned Behavior

Maksut, Eaton, Siembida, Driffin, \& Baldwin, 2016). Using structural equation modeling, Wulfert and Wan (1993) found that higher social norm perceptions and perceived consequences to condom use predicted higher levels of self-efficacy (a mediating variable), which in turn predicted higher levels of condom use (Basen-Engquist, 1992; Wulfert \& Wan, 1995).

\section{The Information-Motivation-Behavioral Skills Model}

The Information-Motivation-Behavioral Skills (IMB) model suggests that safer sex behavior results from information about sexual health risks (e.g., HIV infection), motivation to reduce these risks, and behavioral skills for reducing such health risks (Fisher \& Fisher, 1992). Motivation is influenced by attitudes and perceived norms for the sexual health behavior

Attitudes and subjective norms will be influenced by perceived vulnerability to HIV and perceived benefits/barriers to the sexual health behavior (Fisher, Fisher, Williams, \& Malloy, 1994). Risk reduction information and motivation are correlated and each predict behavioral skills, which predicts actual risk reduction behavior (Fisher \& Fisher, 1992).

Research has supported the IMB model as a basis for AIDS prevention programs among Caucasian gay men (Nostlinger et al., 2011). Portions of the IMB model have been used in a study of African men who have sex with men (Kaighobadi, Knox, Reddy, \& Sandfort, 2014). Research that used 


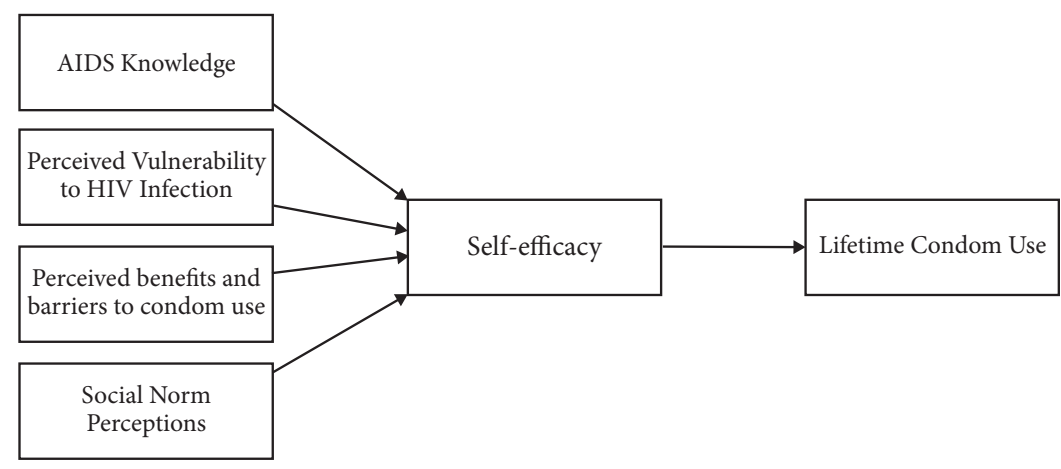

Fig. 3. Visualization of the Information-Motivation-Behavioral Skills Model.

structural equation modeling has supported the overall IMB model in samples of gay men and university students (Fisher et al., 1994; Horvath, Smolenski, \& Amico, 2014).

The unique behavioral skills component of the IMB model is related to self-efficacy and sexual assertiveness. Self-efficacy has been added to models of health behavior, but sexual assertiveness has not. Assertiveness ensures that a person maintains expressed desires and goals for condom use without yielding to pressures to abandon safer sex practices (Kelly \& Kalichman, 1995; Santos-Iglesias \& Sierra, 2010). Sexual assertiveness is a skill that can be learned to practice safer sex behaviors for mentally ill women (Weinhardt, Carey, Carey, \& Verdecias, 1998) and gay men (Kelly, St. Lawrence, Betts, Brasfield, \& Hood, 1990).

\section{Comparing the Theories}

Fisher and Fisher (1992) contend that the TRA model is not adequately comprehensive because it only focuses upon attitudinal aspects of HIV prevention and excludes behavioral skills (see also Manstead, 2011). The IMB model includes skills for safer sex practices, but the motivation component remains deceptively simplistic. Motivation to engage in safer sex behavior depends upon several concepts: perceived severity, perceived benefits/barriers, attitudes toward safer sex, and subjective norms for safer sex (Fisher et al., 1994). Motivational factors should be specified in an integrative model of sexual health behavior (Wulfert, Wan, \& Backus, 1996).

These models have not been tested with socio-cultural factors. Theories 
of sexual health behavior need to account for the contextual factors associated with a minority community to identify pertinent determinants of sexual risk behaviors (e.g., Mustanski, Lyons, \& Garcia, 2011). A contextual factor for gay men is socialization into a sexual orientation subculture. Gay socialization refers to degree of coming out, involvement in gay activities, and self-identification as a gay male (Vanable, McKirnan, \& Stokes, 1998). Seibt et al. (1995) found that higher levels of gay socialization were associated with higher levels of condom use during anal intercourse.

Prior studies of these models often test differences between groups or use regression analyses to test the model. These techniques do not truly test the model as a whole because they do not permit a simultaneous test of multiple paths in the model. Structural equation modeling performs a simultaneous test of multiple paths and can identify superfluous aspects of the model that can be eliminated or new variables (e.g., gay socialization) that can be added to enhance the overall model's predictive ability (Kline, 1998). Of the few studies that have used structural equation modeling to examine these models, some do not measure the entire model or have methodological flaws, such as unreliable instrumentation or using a single question to measure a construct (e.g., Brunswick \& Banaszak-Holl, 1996; Ford \& Norris, 1995).

Prior research (Flowers, Sheeran, Beail, \& Smith, 1997) suggests that several theoretical concepts from models of sexual health behavior (i.e., attitudes toward safer sex, self-efficacy, and social norms) help predict sexual risks among gay/bisexual men. Unfortunately, most of these studies did not examine ethnic minority gay/bisexual men.

\section{Hypotheses}

The TRA model in its basic form was hypothesized to fit the data moderately well. In a test of the Theory of Planned Behavior, higher levels of self-efficacy (i.e., perceived behavioral control) were hypothesized to predict higher levels of safer sex intentions. Because self-efficacy has been described as a mediator in key theoretical papers (e.g., Bandura, 1990) and in empirical research (e.g., Wulfert \& Wan, 1993), self-efficacy was also examined as a mediator of the attitude and subjective norm dimensions and safer sex intentions. Positive attitudes (fewer expected consequences) and higher levels of social norms were hypothesized to predict higher levels of self-efficacy, which were hypothesized to predict higher levels of safer sex intentions. 
The basic IMB model was hypothesized to fit the data at least moderately well. Thus, higher levels of HIV knowledge and higher levels of motivation were hypothesized to predict greater levels of behavioral skills, which should predict greater levels of safer sex behavior.

Lower levels of perceived barriers and higher levels of gay socialization, sexual assertiveness, social norm perceptions, and perceived benefits were theorized to predict higher levels of self-efficacy, which were theorized to predict higher levels of safer sex intentions; in turn, higher intentions were hypothesized to predict higher levels of reported safer sex behavior. This hypothesized integrative model brings together key variables based on prior research that integrates sexual health models (e.g., Wulfert et al., 1996).

\section{Method}

\section{Participants and Procedure}

Participants were 151 African-American gay/bisexual men aged 18 years or older. The sample primarily consisted of adults (mean age $=36.77$ years) who were single $(47.7 \%)$ and labeled their sexual orientation as "gay" $(72.8 \%)$. About $55 \%$ of the sample's yearly income was $\$ 20,000$ or less. Those with a prior sexually transmitted infection (STI) other than HIV (52.3\%) had contracted gonorrhea (15.2\%), syphilis (7.9\%) or multiple STIs (11.9\%). Most had been tested for HIV (96\%) and $45.7 \%$ indicated they were HIV positive.

The data from this study were taken from a larger project investigating the sexual health behaviors of African-American gay/bisexual men (Blinded Citation). Participants were recruited in Chicago, IL (USA) through newspaper advertisements, outreach in community settings, and snowball sampling techniques. This city was chosen because of convenience and because of the city's diversity.

Men were invited to call a local university about a confidential study concerning safer sex and "African-American men who have sex with men." The advertisement stated that the study would last about 60 minutes and volunteers would be paid $\$ 20$. Men who called were screened for eligibility (i.e., they had to be 18 years or older, identify as engaging in sexual activity with other men, have at least 8 years of formal education, and be in fair or good medical condition). Individuals who met these criteria were given an appointment at the university. The measures were presented in a counterbalanced order. Each participant received a debriefing form. 


\section{Measures}

Participants completed a demographic form in which they provided information regarding age, sex, relationship status, race/ethnicity, education level, religious affiliation, frequency of attending religious services, and sexual orientation. Next, they completed the following scales:

The shortened, Form X-1 of the Marlowe-Crowne Social Desirability Scale (MCSDS; Strahan \& Gerbasi, 1972) was used as a measure of the tendency of participants to give socially desirable responses. The Form X-1 version correlates well with the full MCSDS and has adequate internal consistency reliability $(\mathrm{KR}-20=.88)$. The MCSDS has been shown to be valid compared to other measures (Lambert, Arbuckle, \& Holden, 2016). In the current study, this 10-item scale had a KR-20 $=.78$.

The Perceived Risk subscale from the Condom Attitude Scale (CAS; Sacco, Levine, Reed, \& Thompson, 1991) was used in the study to assess a person's perceived risk for HIV infection. Participants indicated their agreement ( $\mathrm{o}=$ strongly disagree to $6=$ strongly agree) with 6 statements. Derived via factor analysis, this subscale has shown adequate reliability and validity (Sacco et al., 1991; Cronbach's alpha $=.73$ in this study). The CAS is frequently used in safer sex research (e.g., McGrane Minton, Mittal, Elder, \& Carey, 2016)

The Multidimensional Condom Attitudes Scale (MCAS) (HelwegLarsen \& Collins, 1994) was used to assess perceived benefits and barriers to condom use. The 25-item MCAS contains five subscales: ReliabilityEffectiveness, Pleasure, Identity Stigma, Embarrassment about Negotiation and Use, and Embarrassment about Purchase. Respondents indicate their level of agreement with statements regarding aspects of condom use. The subscales were validated via factor analyses and all show good internal reliability across several studies (Helweg-Larsen \& Collins, 1994; Starosta, Berghoff, \& Earleywine, 2015). In this study, Cronbach's alpha $=.82$.

The MCAS does not adequately address partner reactions as perceived benefits/barriers to condom use. Thus, the Partner Barriers subscale from the Condom Barriers Scale (PB-CBS) (Cronbach's alpha $=.86$ to .90$)$ (St. Lawrence et al., 1999) was used as an additional scale to assess perceived benefits/barriers (Fogel et al., 2015). This 8-item scale had a Cronbach's al$\mathrm{pha}=.90$ for this study.

The Intention subscale from the Sexual Risks Scale (DeHart \& Birkimer, 1997) was used to measure intention to try to practice safer sex. Participants 
indicated to what degree 7 items were self-descriptive. This measure has acceptable internal reliability (Cronbach's alpha $=.86$ ) and construct validity (DeHart \& Birkimer, 1997; Gooden et al., 2016). In this study, Cronbach's alpha $=.78$.

The Normative Beliefs subscale from the SRS was also used. This scale assessed perceived pressure from peers to practice safer sex. Participants indicated to what degree 7 items were self-descriptive. In this study, Cronbach's alpha $=.78$.

The Condom Use Self-Efficacy Scale (CUSES) (Brien, Thombs, Mahoney, \& Wallnau, 1994) was used to assess people's perceived ability to use condoms in a variety of situations (see also Gooden et al., 2016). Participants indicated their level of agreement with 28 statements. The CUSES showed good internal consistency in the current study (Cronbach's alpha $=.93$ ).

The Identification and Involvement with the Gay Community Scale (Vanable et al., 1998) was used to assess perceived closeness with the gay community and involvement in gay-related social activities (e.g., reading a gay-oriented paper). This scale has shown adequate reliability (Cronbach's alpha $=.78$; test-retest $=.74$ ), and reasonable construct validity (Vanable et al., 1998; Puckett, Levitt, Horne, \& Hayes-Skelton, 2015). In the current study, this 8 -item scale had a Cronbach's alpha $=.75$.

The 24-item short form AIDS Risk Knowledge was used for this study (Cronbach's alpha $=.71$ ) (St. Lawrence, 1993). Higher scores indicate greater AIDS knowledge.

Morokoff et al. (1997; 2009) developed an 18-item Sexual Assertiveness Scale for women that was adapted for use with men. Participants indicate how often they behave in accordance with each statement (from $\mathrm{a}=$ never, $\circ \%$ of the time to e=always, $100 \%$ of the time). A mean was calculated, and higher scores indicate greater levels of perceived sexual assertiveness.

A Sexual Behavior Inventory was developed for this study. Using a 5-point Likert-type scale, participants were asked to estimate the number of times they engaged in penile-vaginal intercourse, receptive anal intercourse, and insertive anal intercourse. Next, respondents were asked to indicate how often (e.g., $75 \%$ of the time) they engaged in these sexual activities with condoms. Responses across sexual behaviors were averaged to obtain lifetime condom use in vaginal and anal sex. 


\section{Results}

An alpha level of .01 was selected as the criterion for statistical significance to reduce Type I error. The scales showed adequate internal reliability. Social desirability was not significantly associated with the measures.

Path analyses were conducted via structural equation modeling using LISREL with the covariance matrix of measured variables as input (Joreskog \& Sorbom, 1996). Path analysis assumes that the measured variables have no measurement error (Kline, 1998). This drawback can be addressed via a sensitivity analysis, which involves conducting a path analysis, specifying the estimated error terms for each indicator, and examining the impact on path coefficients in the model (Kline, 1998). Although some correlations could exist between some related independent variables, the models were being conceptualized as a group of characteristics and skills that develop independently and influence safer sex behaviors.

The goodness of fit index (GFI), the comparative fit index (CFI), and the incremental fit index (IFI) were used to gauge model fit (Joreskog \& Sorbom, 1996). The GFI reflects how well the overall variance-covariance matrix explains the measured variables. The CFI and IFI indicate how much better the given model fits the data relative to a null model in which sampling error is assumed to explain the interrelationships (Tanaka, 1993). The indices can range from zero to one. Fit indices above .90 are viewed as a minimum satisfactory level of model fit (Kline, 1998).

\section{Testing the Theory of Reasoned Action}

In the test of the basic TRA model, the path coefficients were all significant and in the hypothesized direction. Accordingly, more positive attitudes toward condoms $(\beta=.25, \mathrm{~d}=.36, p<.01)$, fewer partner barriers to condom use ( $\beta=-.18, d=.33, p<.01)$, and higher social norm beliefs for safer $\operatorname{sex}(\beta=.27, \mathrm{~d}=.47, p<.01)$ predicted greater safer sex intentions. The fit for this model was perfect: GFI, CFI, and IFI $=1$.o. The social norms scale and the safer sex intentions scale are subscales from the same instrument; thus, the significant path coefficient between these two variables could reflect shared method variance. As a check, the model was run again with an alternative measure of social norms used in the larger study. The results were virtually identical.

With self-efficacy as an independent variable, the Theory of Planned Behavior model had the same perfect fit. All four path coefficients were in the 


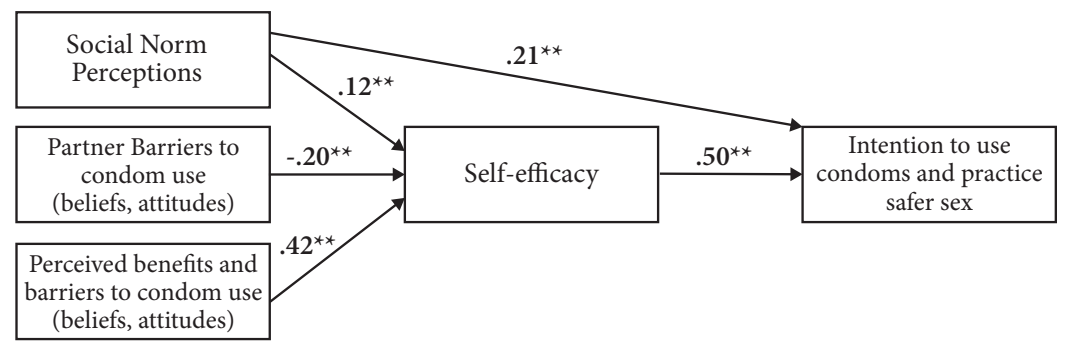

Fig. 4. Test of the Theory of Reasoned Action model with Self-efficacy as a mediator. Significant path coefficients have an " ”" for the .05 level or an "**» for the .01 level. Two nonsignificant paths from the beliefs/attitudes dimensions to intentions have not been drawn.

hypothesized direction, but only the paths with social norms ( $\beta=.21, \mathrm{~d}=.39$, $p<.01)$ and self-efficacy $(\beta=.50, d=.47, p<.01)$ were statistically significant. The two attitude measures were significantly related to safer sex intentions in prior tests; their statistically insignificant paths in the current model were clearly affected by the addition of self-efficacy as an independent variable.

The next test involved self-efficacy as a mediator.

The three independent variables were allowed to predict self-efficacy and safer sex intentions. Higher levels of perceived benefits to condom use $(\beta=.42, \mathrm{~d}=.54, p<.01)$, lower levels of partner barriers $(\beta=-.20, \mathrm{~d}=.47, p<.01)$, and higher levels of social norms for condom use $(\beta=.12, \mathrm{~d}=.19, p<.01)$ all predicted higher levels of self-efficacy. Also, higher levels of self-efficacy predicted higher safer sex intentions $(\beta=.50, \mathrm{~d}=.47, p<.01)$. The direct effects of the independent variables on safer sex intentions were in the hypothesized direction, but only one path was significant: Higher levels of social norms predicted higher safer sex intentions $(\beta=.21, \mathrm{~d}=.39, p<.01)$.

As a check of a mediational effect, the path between social norms and safer sex intentions was constrained to zero. The resulting difference in chisquare between the two models (change in $\chi^{2}=10.64$ ) was statistically significant $(p<.01)$, indicating the direct path added to the model. Self-efficacy does not appear to mediate the relationship between social norms and safer sex intentions because the direct relationship between the latter two variables remains statistically significant $(p<.01)$ and the difference of chisquares test was significant. This model showed a very good fit. Most of the variance in the model was explained (GFI=.99) and the model was shown to be better relative to a null model ( $\mathrm{CFI}$ and $\mathrm{IFI}=1.0)$. 


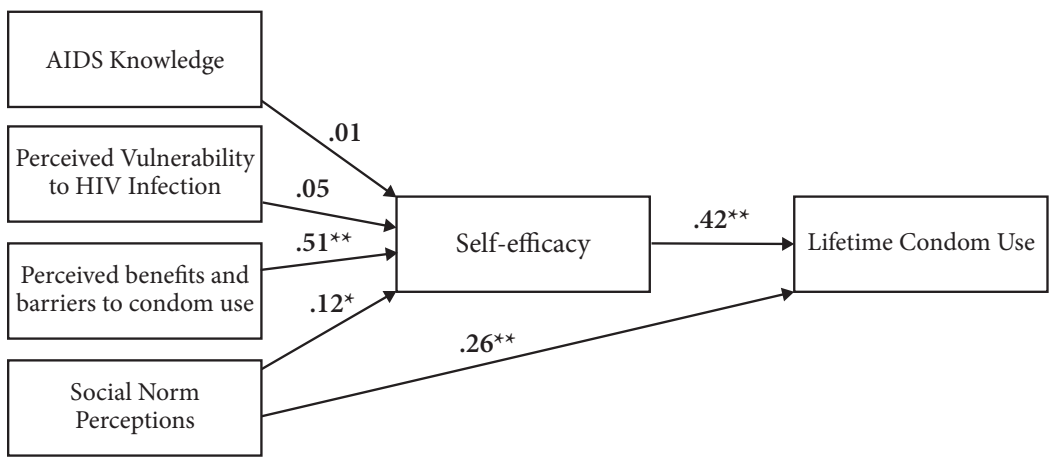

Fig. 5. Test of the generic Information-Motivation-Behavioral Skills Model. Significant path coefficients have an "*” for the .05 level or an "**” for the .01 level. Three non-significant paths from the knowledge, vulnerability, and benefits/barriers dimensions to condom use have not been drawn.

\section{Testing the Information-Motivation-Behavioral Skills Model}

The results of the basic IMB model test were mixed. The model fit was perfect. The path coefficients between the four independent variables and self-efficacy were all in the hypothesized direction, but only two were statistically significant. Stronger levels of self-efficacy were predicted by more positive attitudes toward condoms $(\beta=.51, \mathrm{~d}=.54, p<.01)$, higher social norm beliefs for safer sex $(\beta=.12, \mathrm{~d}=.26, p<.013)$, higher levels of AIDS knowledge, and greater levels of perceived vulnerability to HIV infection.

The pattern was similar for the direct effect of each independent variable on actual condom use, but only the path with social norms was statistically significant $(\beta=.26, d=.36, p<.01)$. Finally, higher levels of self-efficacy predicted higher levels of lifetime condom use $(\beta=.42, \mathrm{~d}=.37, p<.01)$.

A set of tests were conducted to determine whether or not self-efficacy mediates the relationship between perceived benefits to condom use and lifetime condom use. The direct path between perceived benefits and lifetime condom use was constrained to zero. The resulting difference in chisquare between the first model test and this test $\left(\chi^{2}=.04\right)$ was not statistically significant $(p>.01)$, indicating the direct path did not add to the model. Self-efficacy appears to mediate the relationship between perceived benefits and lifetime condom use. Self-efficacy does not appear to mediate the relationship between social norms and lifetime condom use because the direct relationship between the latter two variables remains statistically significant 


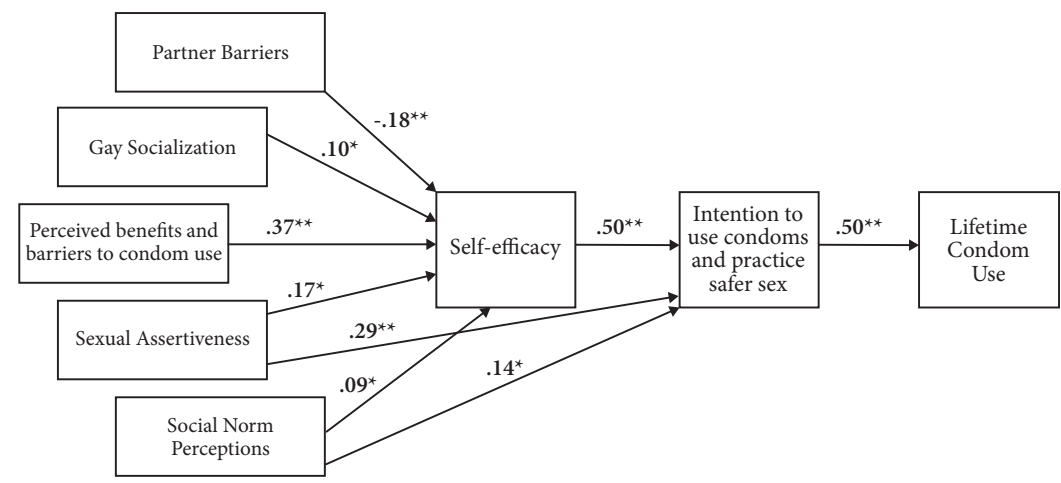

Fig. 6. Test of the Integrated Model with lifetime condom use. Significant path coefficients have an "*” for the .05 level or an "**” for the .01 level.

$(p<.01)$ in the current model and the difference of chi-squares test was also significant (Holmbeck, 1997).

\section{Testing the Integrative Model}

The first test of an integrative model included variables based on theory and the prior results of this study. Because the prior models did not include gay socialization or sexual assertiveness as independent variables, both were added to the integrated model. Thus, the first test of an integrative model included the following independent variables: perceived benefits, partner barriers, social norm perceptions, sexual assertiveness, and gay socialization.

The paths were in the hypothesized direction and were significant at the .o1 level or exhibited a statistical trend for significance at the .05 level.

Higher levels of self-efficacy were predicted by more positive condom attitudes $(\beta=.37, \mathrm{~d}=.54, p<.01)$, fewer partner barriers $(\beta=-.18, \mathrm{~d}=.44, p<.01)$, greater social norm perceptions for safer $\operatorname{sex}(\beta=.09, \mathrm{~d}=.21, p<.038)$, greater sexual assertiveness $(\beta=.17, \mathrm{~d}=.25, p<.016)$, and higher levels of gay socialization $(\beta=.10, d=.20, p<.044)$. Higher levels of self-efficacy significantly predicted greater safer sex intentions $(\beta=.50, \mathrm{~d}=.54, p<.01)$. Greater levels of social norm perceptions $(\beta=.14, \mathrm{~d}=.26, p<.014)$ and sexual assertiveness $(\beta=.29, d=.36, p<.01)$ significantly predicted greater safer sex intentions. Greater safer sex intentions significantly predicted higher levels of lifetime condom use $(p<.01)$. The overall fit of this model was strong, accounting for most of the variance in the model $(\mathrm{GFI}=.97)$ and a significant improvement over a null model (CFI and IFI=1.0). 
Several difference of chi-square tests were conducted to determine if previously untested paths significantly added to the overall integrated model. Including gay socialization did not add to the model (change in $\chi^{2}=3.54$, $p<.06$ ). Adding social norms-self-efficacy path did not significantly add to the model (change in $\chi^{2}=3.05, p<.09$ ). The sexual assertiveness-self-efficacy path exhibited a statistical trend for significantly adding to the model (change in $\chi^{2}=5.21, p<.025$ ). The social norms-intentions path (change in $\chi^{2}=4.89, p<.05$ ) and sexual assertiveness-intentions path (change in $\chi^{2}=8.85$, $p<.005)$ each significantly added to the model.

Because path analyses assume that the variables have no measurement error and do not permit any modeling of error terms, a sensitivity analysis was conducted on the integrated model in which the error term for each variable was specified. The sensitivity analysis serves to check the integrity of the model by partially accounting for the assumption of zero measurement error. Each indicator for the integrated model was assumed to be $70 \%$ reliable (i.e., an error term of .30 for each variable). The results show that some path coefficients decreased in magnitude and level of statistical significance, the fit indices were not affected, and the overall pattern of results remained unchanged. The findings from this sensitivity analysis support the integrated model.

\section{Discussion}

\section{Implications for the TRA model with African-American gay/bisexual men}

The results of this study provide important information about practical and theoretical aspects of safer sex practices among African-American gay/bisexual men. Like a prior structural equation modeling study with the TRA (Cochran et al., 1992) and a meta-analysis of the TRA (Albarracin, Johnson, Fishbein, \& Muellerleile, 2001), this study supports the basic TRA model in predicting safer sex (see also Kalichman, 2007; McKechnie, Bavinton, \& Zablotska, 2013). The unique aspect of the TRA concerns the inclusion of social norm perceptions. The results support this variable as part of a model of safer sex behavior for African-American gay and bisexual men (McKechnie et al., 2013). The degree to which people think their peers engage in safer sex influences their intention to practice safer sex. Social forces clearly play a role in safer sex practices, which is not surprising given the interpersonal na- 
ture of sex. Other studies have consistently shown social norm perceptions to be predictive of safer sex (Flowers et al., 1997; McKechnie et al., 2013).

In addition to the social norm perceptions dimension, the TRA specifies an attitudes component. The attitudes dimension was measured by two variables. The inclusion of partner barriers as one of these measures highlights the importance of interpersonal concerns (i.e., the influence of a sex partner) in motivating safer sex behavior. If an African-American gay/bisexual man feels that his partner will not be amenable to condom use or other safer sex behavior, his intentions to engage in safer sex practices decrease (Starks, Millar, \& Parsons, 2015). A sex partner's attitudes and reaction to safer sex appear to be important determinants of safer sex behavior. Specifically, a sex partner may have a variety of negative responses to condom use based upon the idea that condom use implies a lack of trust or compromised sexual health (Sanderson \& Maibach, 1996; St. Lawrence et al., 1999). Condom use requires some degree of awareness and willingness of both sexual partners, and an individual who anticipates that his sex partner might be offended by condom use might not initiate this safer sex strategy at all (Sanderson \& Maibach, 1996; Starks et al., 2015).

Self-efficacy appeared to be an important component in the TRA (Wilson et al., 2016). Yet, self-efficacy may not operate as an independent predictor of safer sex intentions, as specified by the Theory of Planned Behavior. Although the overall fit of such a model was perfect, the formerly significant relationship between condom attitudes and safer sex intentions was no longer statistically significant with self-efficacy as an independent variable, which is a pattern of results that has been shown in previous research (Wulfert et al., 1996). Alternatively, self-efficacy does appear to operate as a mediator in the TRA, mediating the relationship between safer sex attitudes and safer sex intentions (see also Escribano, Espada, Morales, \& Orgiles, 2015). Accordingly, an African-American gay/bisexual man's safer sex attitudes influence his feeling of self-efficacy (i.e., his self-confidence for practicing safer sex), which in turn influence his safer sex intentions (Wilson et al., 2016). Other studies support the role of self-efficacy as a mediator in the TRA (O'Leary et al., 2005; Wulfert \& Wan, 1993; Wulfert et al., 1996).

Self-efficacy did not appear to mediate the relationship between social norms and safer sex intentions in this study. Theoretically, social norms should influence self-efficacy, which in turn should influence safer sex intentions (i.e., "if others practice safer sex, I can too"). This pathway has 
not been examined extensively, but results from other studies (Wulfert \& Wan, 1993; Wulfert et al., 1996) suggest that self-efficacy mediates the relationship between social norm perceptions and safer sex intentions (see also Escribano et al., 2015). The lack of this particular mediational effect in the current study could be due to shared variance between the safer sex intentions and the social norms measures; both instruments are subscales of the Sexual Risks Scale, which could artificially enhance the strength of their relationship. However, additional analyses using an alternative measure of social norms (i.e., a measure used in the larger overall study) produced the same results-the expected mediational effect does not occur. The findings in this study may contradict prior research due to varying characteristics in the measures employed; the measures used in the two relevant studies were psychometrically modest (Wulfert \& Wan, 1993; Wulfert et al., 1996). The results from the current study suggest that social norms directly influence safer sex intentions. Clearly, the relationship between self-efficacy and social norms should be investigated further to determine if they operate as independent predictors of safer sex intentions or if self-efficacy mediates the link between social norms and safer sex intentions.

\section{Implications for the IMB model with African-American gay/bisexual men}

The use of the overall IMB model as a framework for safer sex for AfricanAmerican gay/bisexual men was supported in this study, as in previous research with other populations (Fisher et al., 1994; Horvath et al., 2014; Kaighobadi et al., 2014; Nostlinger et al., 2011). Including AIDS knowledge as a component in the IMB model did not appear to be useful. Many studies have shown that AIDS knowledge does not predict safer sex behavior (Kelly et al., 1994; Zellner, 2003). Information is an obvious prerequisite of any behavior, including safer sex behavior. Yet, sexual behavior requires that individuals utilize complex skills, making the importance of AIDS knowledge as an independent predictor of safer sex behavior pale when compared to the other predictors (i.e., perceived benefits, partner barriers, social norms). Although information alone does not predict safer sex behavior, this factor should be included in the IMB model—and support the overall paradigmbecause of the construct's theoretical significance (Fisher et al., 1994; Horvath et al., 2014; Kaighobadi et al., 2014).

The results of the IMB model show that perceived benefits, social norms, and self-efficacy can predict reported condom use among African-American 
gay/bisexual men. Without the non-significant AIDS knowledge variable, this model resembles the TRA model with self-efficacy as a mediator (see also Kalichman, Picciano, \& Roffman, 2008). Like the prior models with safer sex intention, self-efficacy mediated the relationship between perceived benefits and reported condom use.

\section{Implications for an Integrated Model with African-American gay/bisexual men}

Contrasting models of safer sex behavior can stimulate ideas for future research and enhance our understanding of safer sex practices among African-American gay/bisexual men (Hergenrather et al., 2016). The TRA includes attitudes toward safer sex and social norm perceptions of safer sex, both of which consistently predict safer sex intentions. The attitudes dimension is a broad construct that can include attitudes about the health protective behavior, expected outcomes of the behavior, and a sex partner's expected reaction to the behavior. Attitudes can encompass a variety of perceptions, suggesting that the key attitudes need to be specified to enhance the theoretical clarity of the TRA with African-American gay/bisexual men. The IMB model's motivation dimension is akin to the TRA's attitudes and social norms dimension. The IMB model does, however, highlight the importance of behavioral skills (e.g., self-efficacy) in models of safer sex and suggests that actual safer sex behavior be employed as an outcome, rather than safer sex intentions. The TRA could be expanded to include selfefficacy as a mediator and reported safer sex behavior as a dependent variable. Empirical comparisons of safer sex theories support the inclusion of benefits/barriers to condom use, social norm perceptions, and self-efficacy in an integrated model of safer sex practices with African-American gay/ bisexual men (Basen-Engquist, 1992; Horvath et al., 2014; Kaighobadi et al., 2014; McKechnie et al., 2013; Norris \& Ford, 1995; Wulfert \& Wan, 1995). Similarly, sexual assertiveness was easily included in an integrated model. Prior research and the current study show that sexual assertiveness is a key predictor of safer sex intentions.

Adding gay socialization did not appear to improve the integrated model. Theoretically, an African-American gay/bisexual man's level of gay socialization may influence his attitudes toward or social norm perceptions of safer sex. Higher levels of gay socialization should predict more positive condom attitudes and social norm perceptions of safer sex, but only if the gay community espouses such ideas about safer sex. Given the paucity of research 
in this area, the notion of including gay socialization may be theoretically inaccurate. Gay socialization is important to the overall identity structure of African-American gay and bisexual men, but may not strongly influence their attitudes about condoms or social norm perceptions of safer sex.

Still, a distinction must be made between the theoretical, statistical, and practical significance of variables that are hypothesized to influence safer sex practices. Although factors like gay socialization or AIDS knowledge were not statistically significant at the .o1 level in all of the analyses for the current study, there are clear conceptual reasons why these variables are important for safer sex behavior for African-American gay/bisexual men. Interventions must be comprehensive and include factors that have a practical significance for the promotion of safer sex behavior. AIDS knowledge does not directly predict safer sex practices by statistical standards, but it is an obvious prerequisite for any sexual health behavior and must be included in safer sex intervention programs. Thus, variables that are not statistically significant should not be automatically ignored; such variables may have great theoretical and practical significance in promoting safer sex behavior.

\section{Clinical Implications and Conclusions}

The findings may be limited by some combination of participants' selfserving biases, demand characteristics, and the artificial nature of the research setting. Participants may have been motivated by the monetary compensation and had to be comfortable enough to complete the survey at a local university. Thus, they may not be representative of all AfricanAmerican gay/bisexual men. Only one city was used for this sample, and the results may not generalize to other samples in which factors related to safer sex behaviors may differ. Despite these limitations, this study has important implications for public health interventions and future research on African-American gay/bisexual men. Using the integrated model, intervention strategies should promote positive safer sex attitudes, favorable social norm perceptions of safer sex, and high levels of self-efficacy among African-American gay/bisexual men in social media and venues that African-American gay/bisexual men frequent. Community agencies could implement workshops for African-American gay/bisexual men where sexual assertiveness skills are taught and rehearsed (e.g., Kalichman et al., 1996). Local organizations could also sponsor recreational activities among African-American gay/bisexual men where safer sex behavior is a recurring 
theme. Important research is being conducted with African-American gay/ bisexual men and safer sex issues, but this research does not consistently use theory-based models (Hergenrather et al., 2016). For example, the relationship between spirituality and safer sex has been examined in some studies (Watkins et al., 2016) while other studies have examined cultural messages about condom use among African-American gay/bisexual males (Harper, Tyler, Bruce, Graham, \& Wade, 2016). These important ideas should be examined in future research by using the integrated safer sex theory espoused in this paper. By employing theories of safer sex, researchers and clinicians will be more effective in promoting sexual health behavior among AfricanAmerican gay/bisexual men.

Brian D. Zamboni, PhD, is faculty in the University of Minnesota Program in Human Sexuality. He is an AASECT certified sex therapist and sexuality educator. In addition to therapy services, he teaches undergraduate and graduate courses in human sexuality and helps train medical students and other professionals. Dr. Zamboni's research focuses on sexual health, sex education, and marginalized populations.

\section{References}

Ajzen, I. (1988). Attitudes, behavior, and personality. Chicago: The Dorsey Press.

Ajzen, I. (1991). The theory of planned behavior. Organizational Behavior and Human Decision Processes, 50, 179-211.

Albarracin, D., Gillette, J. C., Earl, A. N., Glasman, L. R., Durantini, M. R., \& Ho, M. H. (2005). A test of major assumptions about behavior change: A comprehensive look at the effects of passive and active HIV-Prevention interventions since the beginning of the epidemic. Psychological Bulletin, 131, 856-897.

Albarracin, D., Johnson, B. T., Fishbein, M., \& Muellerleile, P. A. (2001). Theories of reasoned action and planned behavior as models of condom use: A meta-analysis. Psychological Bulletin, 127, 142-161.

Bandura, A. (1990). Perceived self-efficacy in the exercise of control over AIDS infection. Evaluation and Program Planning, 13, 9-17.

Basen-Engquist, K. (1992). Psychosocial predictors of safer sex behaviors in young adults. AIDS Education and Prevention, 4, 120-134.

Brien, T. M., Thombs, D. L., Mahoney, C. A., \& Wallnau, L. (1994). Dimensions of selfefficacy among three distinct groups of condom users. Journal of American College Health, 42, 167-174.

Brunswick, A. F. \& Banaszak-Holl, J. (1996). HIV risk behavior and the health belief model: An empirical test in an African American community sample. Journal of Community Psychology, 24, 44-65.

Cochran, S. D., Mays, V. M., Ciarletta, J., Caruso, C., \& Mallon, D. (1992). Efficacy of the theory of reasoned action in predicting AIDS-related sexual risk reduction among gay men. Journal of Applied Social Psychology, 22, 1481-1501. 
Crawford, I., Allison, K., Zamboni, B. D., \& Soto, T. (2002). The influence of dual identity development on the psychosocial functioning of African-American gay and bisexual men. Journal of Sex Research, 39, 179-189.

David, S. \& Knight, B. G. (2008). Stress and coping among gay men: Age and ethnic differences. Psychology and Aging, 23, 62-69.

DeHart, D. D., \& Birkimer, J. C. (1997). Trying to practice safer sex: development of the sexual risks scale. Journal of Sex Research, 34, 11-25

Escribano, S., Espada, J. P., Morales, A., \& Orgiles, M. (2015). Mediation analysis of an effective sexual health promotion intervention for Spanish adolescents. AIDS and Behavior, 19, 1850-1859.

Fishbein, M., \& Ajzen, I. (1975). Belief, attitude, intention, and behavior: An introduction to theory and research. Reading, MA: Addison-Wesley.

Fisher, J. D., \& Fisher, W. A. (1992). Changing AIDS-risk behavior. Psychological Bulletin, 111, 455-474.

Fisher, J. D., Fisher, W. A., Williams, S. S., \& Malloy, T. E. (1994). Empirical tests of an information-motivation-behavioral skills model of AIDS-preventive behavior with gay men and heterosexual university students. Health Psychology, 13, 238-250.

Flowers, P., Sheeran, P., Beail, N., \& Smith, J. A. (1997). The role of psychosocial factors in HIV risk reduction among gay and bisexual men: A quantitative review. Psychology and Health, 12, 197-230.

Fogel, C. I., Crandell, J. L., Neevel, A. M., Parker, S. D., Carry, M., White, B. L., Fasula, A. M., Herbst, J. H., \& Gelaude, D. J. (2015). Efficacy of an adapted HIV and sexually transmitted infection prevention intervention for incarcerated women: A randomized controlled trial. American Journal of Public Health, 105, 802-809.

Ford, K. \& Norris, A. E. (1995). Factors related to condom use with casual partners among urban African-American and Hispanic males. AIDS Education and Prevention, 7, 494-503.

Godin, G., Savard, J., Kok, G., Fortin, C., \& Boyer, R. (1996). HIV seropositive gay men: Understanding safe sexual practices. AIDS Education and Prevention, 8, 529-545.

Gooden, L., Metsch, L. R., Pereyra, M. R., Malotte, C. K., Haynes, L. F., Douaihy, A. Chally, J., Mandler, R. N., \& Feaster, D. J. (2016). Examining the efficacy of HIV riskreduction counseling on the sexual risk behaviors of a national sample of drug abuse treatment clients: Analysis of subgroups. AIDS and Behavior, 20, 1893-1906.

Harper, G. W., Tyler, A., Bruce. D. Graham., L. \& Wade, R. M. (2016). Drugs, sex, and condoms: Identification and interpretation of race-specific cultural messages influencing black gay and bisexual young men living with HIV. American Journal of Community Psychology. [Epub ahead of print]

Helweg-Larsen, M. \& Collins, B. E. (1994). The UCLA multidimensional condom attitudes scale: Documenting the complex determinants of condom use in college students. Health Psychology, 13, 224-237.

Hergenrather, K. C., Emmanuel, D., Durant, S., \& Rhodes, S. D. (2016). Enhancing HIV prevention among young men who have sex with men: A systematic review of HIV behavioral interventions for young gay and bisexual men. AIDS Education and Prevention, 28(3), 252-271. 
Horvath, K. J., Smolenski, D., \& Amico, K. R. (2014). An empirical test of the Information Motivation-Behavioral Skills model of ART adherence in a sample of HIVpositive persons primarily in out-of-HIV-care settings. AIDS Care, 26, 142-151.

Jemmott, J. B., Jemmott, L., O’Leary, A., Icard, L. D., Rutledge, S. E., Stevens, R., Hsu, J., \& Stephens, A. J. (2014). On the Efficacy and Mediation of a One-on-One HIV Risk-Reduction Intervention for African American Men Who Have Sex With Men: A Randomized Controlled Trial. AIDS and Behavior, 19, 1247-1262.

Joreskog, K. G., \& Sorbom, D. (1996). LISREL 8: User's reference guide. Chicago, IL: Scientific Software International.

Kaighobadi, F., Knox, J., Reddy, V., \& Sandfort, T. (2014). Age and sexual risk among Black men who have sex with men in South Africa: The mediating role of attitudes toward condoms. Journal of Health Psychology, 19, 1271-1278.

Kalichman, S. C. (2007). The theory of reasoned action and advances in HIV/AIDS prevention. In I. Ajzen, D. Albarracin, \& R. Hornik (Eds.), Prediction and change of health behavior: Applying the reasoned action approach. (pp. 265-272). Mahwah, NJ, US: Lawrence Erlbaum Associates Publishers.

Kalichman, S. C., Picciano, J., \& Roffman, R. (2008). Motivation to Reduce HIV Risk Behaviors in the Context of the Information, Motivation and Behavioral Skills (IMB) Model of HIV Prevention. Journal of Health Psychology, 13, 680-689.

Kelly, J. A., \& Kalichman, S. C. (1995). Increased attention to human sexuality can improve HIV-AIDS prevention efforts: Key research issues and directions. Journal of Consulting and Clinical Psychology, 63, 907-918.

Kelly, J. A., Murphy, D. A., Washington, C. D., Wilson, T. S., Koob, J. J., Davis, D. R., Ledezma, G., \& Davantes, B. (1994). The effects of HIV/AIDS intervention groups for high-risk women in urban clinics. American Journal of Public Health, 84, 1918-1922.

Kelly, J. A., St. Lawrence, J. S., Betts, R. A., Brasfield, T. L., \& Hood, H. V. (1990). A skillstraining group intervention model to assist persons in reducing risk behaviors for HIV infection. AIDS Education and Prevention, 2, 24-35.

Kline, R. B. (1998). Principles and practice of structural equation modeling. New York: The Guilford Press.

Knox, J., Sandfort, T., Yi, H., Reddy, V., \& Maimane, S. (2011). Social vulnerability and HIV testing among South African men who have sex with men. International Journal of STD \& AIDS, 22, 709-713.

Lacefield, K., Negy, C., Schrader, R. M., \& Kuhlman, C. (2015). Comparing psychosocial correlates of condomless anal sex in HIV-diagnosed and HIV-nondiagnosed men who have sex with men: A series of meta-analyses of studies from 1993-2013. LGBT Health, 2, 200-220.

Lambert, C. E., Arbuckle, S. A., \& Holden, R. R. (2016). The Marlowe-Crowne Social Desirability Scale outperforms the BIDR Impression Management Scale for identifying fakers. Journal of Research in Personality, 61, 80-86.

Maksut, J. L., Eaton, L. A., Siembida, E. J.,Driffin, D. D., \& Baldwin, R. (2016). An evaluation of factors associated with sexual risk taking among black men who have sex with men: A comparison of younger and older populations. Journal of Behavioral Medicine, 39, 665-674. 
Manstead, A. S. R. (2011). The benefits of a critical stance: A reflection on past papers on the theories of reasoned action and planned behaviour. British Journal of Social Psychology, 50, 366-373.

McGrane Minton, H. A., Mittal, M., Elder, H., \& Carey, M. P. (2016). Relationship factors and condom use among women with a history of intimate partner violence. AIDS and Behavior, 20, 225-234.

McKechnie, M. L., Bavinton, B. R., \& Zablotska, I. B. (2013). Understanding of norms regarding sexual practices among gay men: Literature review. AIDS and Behavior, 17, $1245-1254$.

Meyer, I. H. (2010). Identity, stress, and resilience in lesbians, gay men, and bisexuals of color. The Counseling Psychologist, 38, 442-454.

Mitchell, J. W., Garcia, L., Champeau, D., Harvey, S. M., \& Petroll, A. E. (2012). HIVnegative seroconcordant gay male couples' attitudes, intentions, and perceived behavioral control for planned condom use within and outside of their relationships. International Journal of Sexual Health, 24, 239-253.

Morokoff, P., Quina, K., Harlow, L., Whitmire, L., Grimley, D., Gibson, P., Burkholder, G. (1997). Sexual assertiveness scale (SAS) for women: Development and validation. Journal of Personality and Social Psychology, 73, 790-804.

Morokoff, P. J., Redding, C. A., Harlow, L. L., Cho, S., Rossi, J. S.,Meier, K. S., Brown Peterside, B. (2009). Associations of sexual victimization, depression, and sexual assertiveness with unprotected sex: A test of the multi-faceted model of HIV risk across gender. Journal of Applied Biobehavioral Research, 14, 30-54.

Mustanski, B., Lyons, T., \& Garcia, S. C. (2011). Internet use and sexual health of young men who have sex with men: A mixed-methods study. Archives of Sexual Behavior, 40, 289-300.

Norris, A. E., \& Ford, K. (1995). Condom use by low-income African-American and Hispanic youth with a well-known partner: Integrating the health belief model, theory of reasoned action, and the construct accessibility model. Journal of Applied Social Psychology, 25, 1801-1830.

Nostlinger, C., Niderost, S., Platteau, T., Muller, M. C., Stanekova, D., Gredig, D., Roulin, C., Rickenbach, M., \& Colebunders, R. (2011). Sexual protection behavior in HIVpositive gay men: Testing a modified information-motivation-behavioral skills model. Archives of Sexual Behavior, 40, 817-827.

O’Leary, A., Fisher, H. H., Purcell, D. W., Spikes, P. S., \& Gomez, C. A. (2007). Correlates of risk patterns and race/ethnicity among HIV-positive men who have sex with men. AIDS and Behavior, 11(5), 706-715.

O’Leary, A., Wolitski, R. J., Remien, R. H., Woods, W. J., Parsons, J. T., Moss, S., \& Lyles, C. M. (2005). Psychosocial correlates of transmission risk behavior among HIVseropositive gay and bisexual men. AIDS, 19, S67-S75.

Rosario, M., Mahler, K., Hunter, J., \& Gwadz, M. (1999). Understanding the unprotected sexual behaviors of gay, lesbian, and bisexual youths: An empirical test of the cognitive-environmental model. Health Psychology, 18, 272-280.

Puckett, J. A., Levitt, H. M., Horne, S. G., \& Hayes-Skelton, S. A. (2015). Internalized heterosexism and psychological distress: The mediating roles of self-criticism and 
community connectedness. Psychology of Sexual Orientation and Gender Diversity, 2, $426-435$.

Rosenberg E. S., Millett G. A., Sullivan P. S., Del Rio C., \& Curran J. W. (2014). Understanding the HIV disparities between black and white men who have sex with men in the USA using the HIV care continuum: a modeling study. The Lancet HIV, 1, $112-118$.

Sacco, W. P., Levine, B., Reed, D. L., \& Thompson, K. (1991). Attitudes about condom use as an AIDS-relevant behavior: Their factor structure and relation to condom use. Psychological Assessment, 3, 265-272.

Sanderson, C. A., \& Maibach, E. W. (1996). Predicting condom use in African American STD patients: The role of two types of outcome expectations. Journal of Applied Social Psychology, 26, 1495-1509.

Santos-Iglesias, P. \& Sierra, J. C. (2010). The role of sexual assertiveness in human sexuality: A systematic review. International Journal of Clinical and Health Psychology, 10, 553-577.

Seibt, A. C., Ross, M. W., Freeman, A., Krepcho, M., Hedrich, A., McAlister, A., Fernandez-Esquer, M. E. (1995). AIDS Care, 7, S85-S88.

Sheeran, P., Abraham, C., \& Orbell, S. (1999). Psychosocial correlates of heterosexual condom use: A meta-analysis. Psychological Bulletin, 125, 90-132.

St. Lawrence, J. S. (1993). African-American adolescents' knowledge, health-related attitudes, sexual behavior, and contraceptive decisions: Implications for the prevention of adolescent HIV infection. Journal of Consulting and Clinical Psychology, 61, 104-112.

St. Lawrence, J. S., Chapdelaine, A. P., Devieux, J. G., O’Bannon, R. E., Brasfield, T. L., \& Eldridge, G. D. (1999). Measuring perceived barriers to condom use: Psychometric evaluation of the condom barriers scale. Assessment, 6, 391-404.

Starks, T. J., Millar, B. M., \& Parsons, J. T. (2015). Predictors of condom use with main and casual partners among HIV-positive men over 50. Health Psychology, 34, $1116-1122$.

Starosta, A. J., Berghoff, C. R., \& Earleywine, M. (2015). Factor structure and gender stability in the Multidimensional Condom Attitudes Scale. Assessment, 22, 374-384.

Strahan, R., \& Gerbasi, K. C. (1972). Short, homogenous versions of the Marlowe Crowne social desirability scale. Journal of Clinical Psychology, 28, 191-193.

Tanaka, J. S. (1993). Multifaceted conceptions of fit in structural equation models. In K.A. Bollen \& J. S. Long (Eds.), Testing structural equation models (pp.10-39). Newbury Park, CA: Sage Publications, Inc.

Thompson-Leduc, P., Clayman, M. L., Turcotte, S., \& Legare, F. (2015). Shared decision making behaviors in health professionals: A systematic review of studies based on the theory of planned behavior. Health Expectations: An International Journal of Public Participation in Health Care \& Health Policy, 18, 754-774.

Vanable, P. A., McKirnan, D. J., \& Stokes, J. P. (1998). Identification and involvementwith the gay community scale. In C. M. David, W. L. Yarber, R. Bauserman, G. Schreer, \& S. L. Davis (Eds.), Handbook of sexuality-related measures (pp. 407 409). Thousand Oaks, CA: Sage Publications. 
Watkins, T. L Jr., Simpson, C., Cofield, S. S., Davies, S., Kohler, C., \& Usdan, S. (2016). The relationship between HIV risk, high-risk behavior, religiosity, and spirituality among black men who have sex with men (MSM): An exploratory study. Journal of Religion and Health, 55, 535-548.

Weinhardt, L., Carey, M., Carey, K., \& Verdecias, R. (1998). Increasing assertiveness skills to reduce HIV risk among women living with a severe and persistent mental illness. Journal of Consulting and Clinical Psychology, 66, 680-684.

Wilson, P. A., Meyer, I. H., Antebi-Gruszka, N., Boone, M. R., Cook, S. H., \& Cherenack, E. M. (2016). Profiles of resilience and psychosocial outcomes among young Black gay and bisexual men. American Journal of Community Psychology, 57, 144-157.

Wulfert, E. \& Wan, C. K. (1993). Condom use: A self-efficacy model. Health Psychology, $12,346-353$.

Wulfert, E. \& Wan, C. K. (1995). Safer sex intentions and condom use viewed from a health belief, reasoned action, and social cognitive perspective. The Journal of Sex Research, 32, 299-311.

Wulfert, E., Wan, C. K., \& Backus, C. A. (1996). Gay men's safer sex behavior: An integration of three models. Journal of Behavioral Medicine, 19, 345-366.

Zellner, S. L. (2003). Condom use and the accuracy of AIDS knowledge in Côte d'Ivoire. International Family Planning Perspectives, 29, 41-47.

Zhang, J., Jemmott, J. B., \& Jemmott, L. S. (2015). Mediation and moderation of an efficacious theory-based abstinence-only intervention for African American adolescents. Health Psychology, 34, 1175-1184. 


\section{Errata}

Two co-authors were unintentionally omitted from the article "An Integrated Model of Safer Sex Practices among African-American Gay and Bisexual Men," of volume 3, number 2:

Isiaah Crawford, Ph.D., University of Puget Sound, 1500 N. Warner St., Tacoma, WA 98416. president@pugetsound.edu Dr. Crawford’s research has focused on HIV prevention, minorities and marginalized populations.

Fred B. Bryant, Ph.D., Loyola University Chicago, 1032 W Sheridan Rd, Chicago, IL, 60660. fbryant@luc.edu Dr. Bryant's research has focused on quality of life, savoring, and test validity. He is an expert in the use of structural equation modeling and advanced statistical techniques. 